\title{
Detection of Mastitis Pathogens by Analysis of Volatile Bacterial Metabolites
}

\author{
K. A. Hettinga, ${ }^{* 1}$ H. J. F. van Valenberg, ${ }^{*}$ T. J. G. M. Lam,† and A. C. M. van Hooijdonk* \\ *Dairy Science and Technology group, Wageningen University and Research Centre, 6700EV Wageningen, the Netherlands \\ †Dutch Udder Health Centre at GD Animal Health Service, 7420AA Deventer, the Netherlands
}

\section{ABSTRACT}

The ability to detect mastitis pathogens based on their volatile metabolites was studied. Milk samples from cows with clinical mastitis, caused by Staphylococcus aureus, coagulase-negative staphylococci, Streptococcus uberis, Streptococcus dysgalactiae, and Escherichia coli were collected. In addition, samples from cows without clinical mastitis and with low somatic cell count (SCC) were collected for comparison. All mastitis samples were examined by using classical microbiological methods, followed by headspace analysis for volatile metabolites. Milk from culture-negative samples contained a lower number and amount of volatile components compared with cows with clinical mastitis. Because of variability between samples within a group, comparisons between pathogens were not sufficient for classification of the samples by univariate statistics. Therefore, an artificial neural network was trained to classify the pathogen in the milk samples based on the bacterial metabolites. The trained network differentiated milk from uninfected and infected quarters very well. When comparing pathogens, Staph. aureus produced a very different pattern of volatile metabolites compared with the other samples. Samples with coagulase-negative staphylococci and $E$. coli had enough dissimilarity with the other pathogens, making it possible to separate these 2 pathogens from each other and from the other samples. The 2 streptococcus species did not show significant differences between each other but could be identified as a different group from the other pathogens. Five groups can thus be identified based on the volatile bacterial metabolites: Staph. aureus, coagulase-negative staphylococci, streptococci (Strep. uberis and Strep. dysgalactiae as one group), E. coli, and uninfected quarters.

Key words: mastitis, headspace, gas chromatographymass spectrometry, artificial neural network

Received December 12, 2007.

Accepted May 23, 2008.

${ }^{1}$ Correponding author: kasper.hettinga@wur.nl

\section{INTRODUCTION}

The most costly disease of dairy cows is mastitis, which is most often caused by bacteria. Although many bacteria can cause mastitis, a limited group of 5 bacterial species (Staphylococcus aureus, CNS, Streptococcus uberis, Streptococcus dysgalactiae, and Escherichia coli) is responsible for approximately $80 \%$ of the Dutch mastitis cases in which bacteria could be cultured from the milk (Barkema et al., 1998). However, no pathogen is detected in over $30 \%$ of clinical mastitis cases (Bradley et al., 2007).

Determination of mastitis-causing pathogens is of great interest, both for choice of treatment of the cow as well as for possible measures that have to be taken on the farm to prevent the spread of mastitis. Currently, determination of the pathogen is generally done by bacteriological culturing (NMC, 2004). This method, however, has the important disadvantage that it is time-consuming. Because the bacteria have to grow before they can be identified based on phenotypic characteristics, it takes a few days before results are available. Other diagnostic methods such as PCR on milk are, although promising, very labor intensive and thus expensive. Moreover, it is difficult to perform PCR directly on milk, as milk is a complex matrix (Yamagishi et al., 2007).

A disadvantage of bacteriological culturing is the existence of false-negative results, in which samples contain too few pathogens to be detected (Sears et al., 1990). The pathogens may also already be dead before sampling. Finally, failure to detect pathogens in samples taken from quarters with clinical mastitis can be caused by contamination of the sample (Zorah et al., 1993). Thus, faster and more accurate methods of pathogen detection could be advantageous, because farmers are earlier able to choose an optimal treatment.

Fast automatic on-line detection of mastitis has been described using the variables milk temperature, milk electrical conductivity, and milk production (Nielen et al., 1994). Similarly, Heald et al. (2000) showed that a classification could be made between 3 types of mastitis (contagious, environmental, or "other" pathogen) using a variety of already available variables from milk 
and herd screening (DHIA program) such as SCC, days in lactation, and (average) milk production. However, none of these methods was able to identify individual mastitis-causing pathogens.

In microbiology, screening of volatile bacterial metabolites for detection and classification purposes is well known. The detection is based on the fact that all microorganisms have their own group of enzymes, producing their own range of volatile metabolites (Gardner et al., 1998; Marilley et al., 2004; Turner and Magan, 2004). Eriksson et al. (2005) used this principle to detect mastitis using an electronic nose. They were able to discriminate between uninfected and infected quarters based on the bacterial metabolites, but they could not differentiate between pathogens. This may be because electronic noses only detect groups of metabolites, but are unable to identify individual metabolites.

For identification of volatile metabolites, other headspace-based chemical analytical methods can be used. An often-used headspace extraction method is solid-phase microextraction (SPME). Solid-phase microextraction uses a fiber coated with a sorbent that extracts volatiles from the headspace of a sample (Arthur and Pawliszyn, 1990). To identify the individual volatile components, SPME is usually coupled to GC/ MS (Marsili, 1999).

In our study, clinical mastitis samples were examined with classical microbiological methods and by headspace analysis for their volatile metabolites, comparing the results of both methods.

\section{MATERIALS AND METHODS}

\section{Milk Samples}

Fifty milk samples from cows with clinical mastitis were selected from the bacteriological diagnostic lab of the Dutch Animal Health Service (Deventer). Samples had first been screened for the presence of bacteria. If 1 of the 5 pathogens of interest (Staph. aureus, CNS, Strep. uberis, Strep. dysgalactiae, or E. coli) was cultured, the remainder of the sample (approximately 5 $\mathrm{mL}$ ) was frozen at $-20^{\circ} \mathrm{C}$ for later use. Ten samples per pathogen were collected.

Ten milk samples of cows without clinical mastitis and with low SCC $(<75,000)$ were used as controls. The samples were supplied by De Ossekampen, the university farm of Wageningen University and Research Centre (Wageningen, the Netherlands). These samples were also kept frozen at $-20^{\circ} \mathrm{C}$ for later use.

Bacteriological culturing was carried out according to National Mastitis Council protocols (NMC, 2004). All plates were incubated at $37^{\circ} \mathrm{C}$ and examined after 24 and $48 \mathrm{~h}$. Because these were milk samples from routine mastitis diagnosis, the milk samples were incubated overnight at $37^{\circ} \mathrm{C}$ to be able to use them again in case of "no growth." Thus, all milk samples were incubated for $14 \mathrm{~h}$ before analysis of their volatile metabolites. Only milk samples from which 1 bacterial species was cultured before incubation of the sample were included in the study.

\section{Analysis of Volatile Metabolites}

Five-milliliter milk samples were preheated in 20$\mathrm{mL}$ vials sealed with silicon/Teflon septa and magnetic caps for $1 \mathrm{~min}$ at $60^{\circ} \mathrm{C}$. Volatile metabolites were extracted from the headspace for 5 min with a $75-\mu \mathrm{m}$ PDMS-carboxen SPME fiber (Supelco, Bellefonte, PA) using the combiPAL autosampler (CTC Analytics AG, Zwingen, Switzerland). The volatile metabolites were thermally desorbed from the fiber by heating it in a Best PTV injector (Thermo-Finnigan, San Jose, CA) with an empty liner for $5 \mathrm{~min}$ at $250^{\circ} \mathrm{C}$. The fiber was subsequently cleaned for $10 \mathrm{~min}$ at $290^{\circ} \mathrm{C}$. A vial with 5 $\mathrm{mL}$ of demineralized water was used as a blank.

Gas chromatographic separation of the volatile components was performed on a Finnigan Trace GC coupled to a Finnigan DSQ mass spectrometer (Thermo-Finnigan). Volatiles were separated on an apolar BPX-5 column of $30 \mathrm{~m}$ length, $0.15 \mathrm{~mm}$ i.d., and $0.25-\mu \mathrm{m}$ film thickness (SGE, Austin, TX). Oven temperature was held at $-30^{\circ} \mathrm{C}$ for $3 \mathrm{~min}$, increased to $230^{\circ} \mathrm{C}$ at $20^{\circ} \mathrm{C} / \mathrm{min}$, followed by $1 \mathrm{~min}$ holding. Helium was used as the carrier gas at a flow rate of $0.6 \mathrm{~mL} /$ min. The MS interface and the ion source were kept at $250^{\circ} \mathrm{C}$. Acquisition was performed in electron impact mode $(70 \mathrm{eV})$ with $2 \mathrm{scans} / \mathrm{s}$; the mass range used was $\mathrm{m} / z 33$ to 250 .

The resulting chromatograms were analyzed using the AMDIS software (NIST, Gaithersburg, MD); data were deconvoluted to obtain pure mass spectra for improved peak identification. Identification of volatile metabolites was based on matching mass spectra and retention time with pure standards, if possible. Otherwise, spectra were compared with the NIST/EPA/ NIH mass spectral database and the Kovats index was compared with data from literature (Acree and Arn, 2004). Peak integration was subsequently performed using the XCalibur software package (Thermo-Finnigan). Peak area was corrected for the blank sample. The peak area, which is in arbitrary units, was used for subsequent statistical analysis.

\section{Statistical Analysis}

The software package SPSS for Windows version 12.0 (SPSS Inc., Chicago, IL) was used for comparisons 
Table 1. Quantity of volatile metabolites in the milk samples ${ }^{1}$

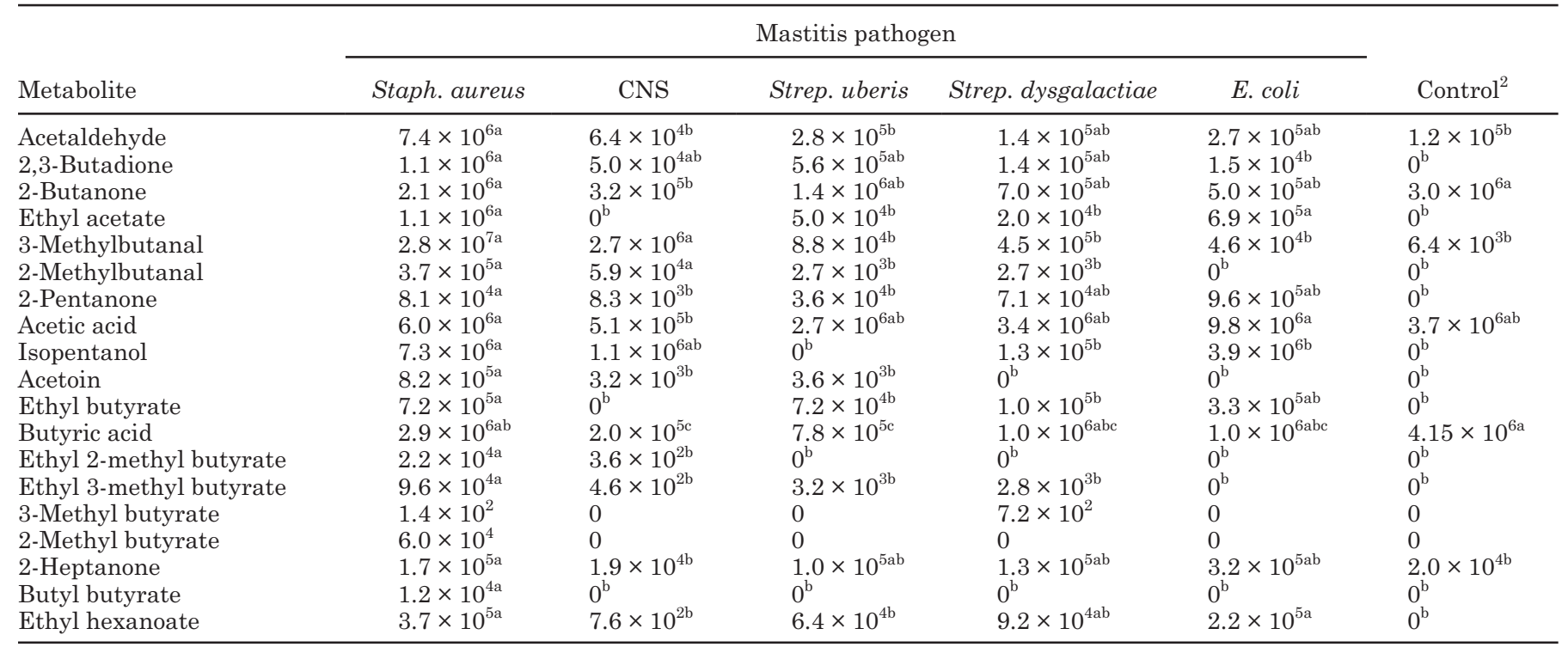

${ }^{a-c}$ Means within a row with different superscripts differ $(P<0.05)$.

${ }^{1}$ Numbers are mean area values (arbitrary units) of the different volatiles of the samples that did contain the compounds of interest.

${ }^{2}$ Milk from cows without clinical mastitis and with low SCC.

between groups. Because data were not normally distributed, the Kruskal-Wallis test was performed first to test for differences between groups. If significant differences between groups were observed, the Nemenyi test (Zar, 1999) was used for subsequent pairwise multiple comparisons.

NeuralTools (Palisade, Ithaca, NY) was used to develop artificial neural networks (ANN). Probabilistic neural networks (PNN) were the type of ANN used for this study. The conjugate gradient descent method was used for training the PNN. Training of the neural networks was carried out using cross-validation, with $70 \%$ of the samples used for training and $30 \%$ for validation. Samples were distributed randomly between the training and validation group. To validate the model, both leave-one-out and 10-fold cross-validation were used.

\section{RESULTS AND DISCUSSION}

\section{Analysis of Volatile Metabolites}

After microbiological analysis of the milk samples, their volatiles were analyzed using GC/MS. Table 1 contains an overview of the results of the GC/MS analysis, grouped by pathogen. The samples from uninfected quarters contained a lower number and lower amount of volatile components, compared with the mastitis milk samples.
The formation of 2-butanone, 2- and 3-methylbutanal, 3-hydroxy-2-butanone (acetoin), and 3-methyl1-butanol (isopentanol) by Staph. aureus has been described by Zechman et al. (1986). Furthermore, the formation of 2- and 3-methylbutanal, as well as the (esters of) branched fatty acids by Staph. aureus has been described by Ritter and Hanni (1960). Of the volatile metabolites found in samples with $E$. coli, acetaldehyde, 2,3-butadione (diacetyl), ethyl acetate, and ethyl butyrate have been described before (Morales et al., 2004). No literature references were found for the volatile metabolites formed by the 2 streptococcus species and CNS.

The univariate statistical analysis of the differences between uninfected and infected quarters showed a clear distinction between the 2 groups. The subsequent statistical analysis of differences between pathogens did not, however, give a clear distinction between the different pathogens (Table 1). Staphylococcus aureus could be differentiated from other pathogens based on the (esters of) the branched fatty acids, such as 2-methyl butyrate. Also, Staph. aureus and E. coli formed a greater amount of ethyl acetate and acetic acid. Staphylococcus aureus and CNS produced similar amounts of the branched aldehydes, which were greater than for the other groups of pathogens. The 2 streptococcus groups did not differ in anyway from each other. 
Five groups can thus be identified based on the statistical analysis of the volatile bacterial metabolites: Staph. aureus, CNS, streptococci (both streptococcus species as one group), E. coli, and culture-negative samples. However, classification based on univariate statistical analysis alone was difficult, because in every group, some samples did have different results compared with the other samples in their group; for example, a specific metabolite was not detected, or the concentration of a specific metabolite was different. Clear classification of the mastitis pathogens in individual samples based on this univariate statistical analysis alone were complicated, time-consuming, and not fully reliable. Therefore, multivariate statistics were used.

\section{Multivariate Statistics}

Many automatic detection techniques depend on multivariate statistics for classification. Among the variety of techniques, ANN are often used. Artificial neural networks are nonlinear models that can be trained to quantify and classify samples based on a large number of input variables. Multilayer perceptrons trained by back-propagation (MLP) are the best known and most commonly applied ANN for classification purposes (González-Arjona et al., 2006).

Another type of ANN is the PNN, which is specifically developed for classification purposes. Unlike other ANN, and like MLP, it is based on well-established statistical principles derived from Bayes decision theory and nonparametric kernel-based estimators of probability density functions. The most important advantages of PNN are the very short training times and the probability per category as output (Specht, 1990; Beltrán et al., 2006).

An ANN consists of simple data processing elements called neurons. Figure 1 gives a schematic representation of a PNN. The number of input neurons is equal to the number of input variables (in our case, the number of volatile components). The data of a test case proceeds from the input layer to the pattern layer. The pattern layer has one neuron for every training case. In the pattern layer, the distance between the test case and all training cases is calculated. The calculated value for the distance is then passed on to the summation layer. The summation layer contains one neuron for every category. All training cases belonging to one category send the value for the distance to their respective summation neuron. This neuron calculates a weighted distance from the test case to the training cases. Finally, all neurons from the summation layer send their output to the output neuron. This output neuron calculates the probability that the test case belongs to any

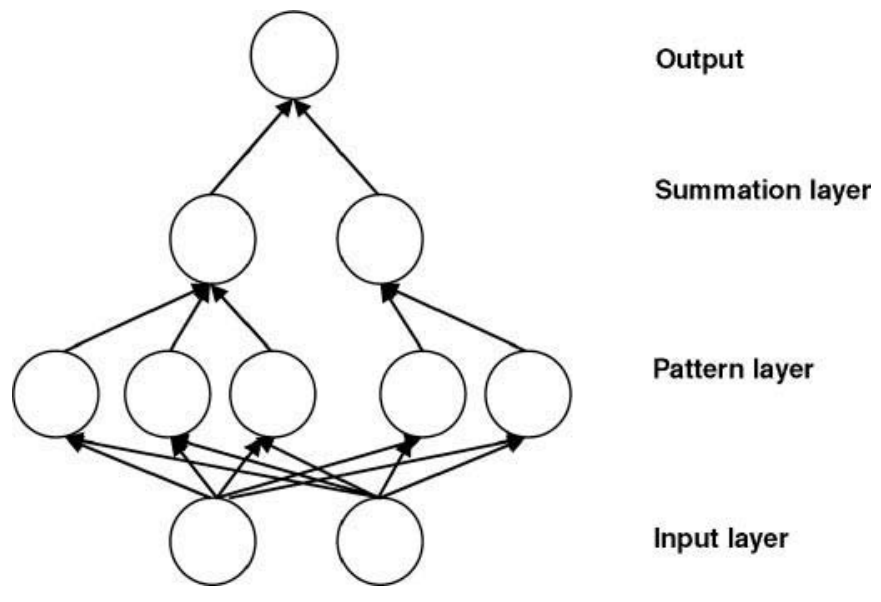

Figure 1. Schematic representation of a probabilistic neural network.

one of the categories. Finally, it selects the category with the smallest average distance (Specht, 1990).

\section{Training the ANN to Classify Milk Samples}

An ANN was first trained to categorize milk as from either uninfected or infected quarters. The correct classification rate for this categorization was $100 \%$. The ANN was then trained for categorizing all 5 pathogens in infected quarters. The correct classification rate for this ANN was $66 \%$ (Table 2). The prediction results showed that the main error was with the 2 streptococcus species, which could not be well classified by the ANN. The bad classification of the 2 types of streptococcus was already expected based on Table 1; all volatile metabolites are formed in approximately equal amounts in both Streptococcus spp. Because of this, for subsequent ANN training, the 2 different Streptococcus spp. were handled as one group.

The ANN was subsequently trained to classify the samples in 4 groups. Table 3 contains the classification results for the validation group. The correct classification rate was $93 \%$, with all samples classified with $>95 \%$ probability. The sample that was incorrectly classified was a CNS sample. The wrongly classified CNS sample differed from the other 9 CNS samples by its relatively low amounts of 2- and 3-methylbutanal.

To confirm the validity of PNN for the relatively small data set, the model was checked using leave-oneout and 10-fold cross-validation. With leave-one-out cross-validation, a correct classification rate of $93 \%$ was obtained. Using 10-fold cross-validation, a correct classification rate of $90 \%$ was reached. This confirms that PNN is a valid data analysis technique for this data. 
Table 2. Cross-validation results of training an artificial neural network (ANN) to differentiate between 5 pathogens

\begin{tabular}{lcccccc}
\hline & \multicolumn{5}{c}{ Predicted by ANN ${ }^{1}$} \\
\cline { 2 - 5 } Microbiological identification & Staph. aureus & CNS & Strep. uberis & Strep. dysgalactiae & E. coli & Correct (\%) \\
\hline Staphylococcus aureus & 3 & 0 & 0 & 0 & 0 & 100 \\
CNS & 0 & 3 & 0 & 0 & 0 & 100 \\
Streptococcus uberis & 0 & 0 & 1 & 1 & 0 & 33 \\
Streptococcus dysgalactiae & 0 & 0 & 2 & 1 & 6 \\
Escherichia coli & 0 & 0 & 0 & & 66 \\
Total correct & & & & & 2 \\
\hline
\end{tabular}

${ }^{1}$ The number of samples classified in the respective group by the ANN.

There is a debate whether mastitis cows from which no pathogens are cultured or those with gram-negative pathogens (e.g., E. coli) in their milk should be treated using antibiotics (Neeser et al., 2006). Rapid classification of samples between no pathogen, $E$. coli, and other pathogens is thus very useful for a treatment decision. Therefore, we trained a new ANN to classify samples in 1 of these 3 groups. The correct classification rate was $94 \%$ (Table 4), with all samples classified with $>95 \%$ probability.

\section{Application in Practice}

The method has been shown to be able to differentiate pathogens based on volatile metabolites. This has two advantages: cost of analysis and analytical time. The cost of a headspace analysis when performed on a large scale may be up to 5 times less compared with classical microbiological culturing. The reduction in analytical time will depend on the necessity of incubation of the samples before analysis of their volatile metabolites. It that respect, it must be emphasized that in this study all samples were incubated overnight before analysis of their volatile metabolites. During this incubation step, bacteria may have further grown and produced more volatile metabolites. This was, however, a necessary step to obtain the samples for this research. Before application of this method in practice, the necessity of the incubation step, and if needed the minimum incuba- tion time, should be determined to achieve maximum reduction in the time needed for analysis.

The results of this study were obtained from milk samples with unambiguous bacteriological results (only one pathogen was detected). Thus, before application in practice, the method needs to be tested in a range of samples from different origins. These results, however, show that mastitis detection and classification using volatile bacterial metabolites looks very promising. Detection of these metabolites can be done using simple and fast analytical equipment. This method may be used for detection of mastitic udder quarters as well as identification of the pathogen causing mastitis.

\section{CONCLUSIONS}

Volatile metabolites found in milk from uninfected quarters differed significantly from metabolites found in milk from infected quarters. Additionally, different pathogens were found to differ in the formation of volatile metabolites. In particular, Staph. aureus, CNS, and $E$. coli differed from the other pathogens. The 2 streptococcus species did not show significant differences between them but were different from the other pathogens. An ANN was trained to classify the milk samples based on the amount of volatile metabolites. The trained ANN was able to differentiate between samples from uninfected and infected quarters, with a correct classification of $100 \%$. Another trained ANN

Table 3. Cross-validation results of training an artificial neural network (ANN) to differentiate between 4 mastitis groups

\begin{tabular}{lccccc}
\hline & \multicolumn{4}{c}{ Predicted by ANN $^{1}$} \\
\cline { 2 - 5 } $\begin{array}{l}\text { Microbiological } \\
\text { identification }\end{array}$ & $\begin{array}{c}\text { Staph. } \\
\text { aureus }\end{array}$ & CNS & Streptococcus & E. coli & Correct (\%) \\
\hline Staphylococcus aureus & 3 & 0 & 0 & 0 & 100 \\
CNS & 0 & 2 & 1 & 0 & 66 \\
Streptococcus & 0 & 0 & 6 & 0 & 100 \\
Escherichia coli & 0 & 0 & 0 & 3 & 100 \\
Total correct & & & & & 93 \\
\hline
\end{tabular}

${ }^{1}$ The number of samples classified in the respective group by the ANN. 
Table 4. Cross-validation results of training an artificial neural network (ANN) to differentiate between gram-positive, gram-negative, and control samples

\begin{tabular}{lcccc}
\hline & \multicolumn{3}{c}{ Predicted by ANN ${ }^{1}$} \\
\cline { 2 - 4 } Microbiological \\
\cline { 2 - 4 } & Gram-positive & Gram-negative & Control & Correct (\%) \\
\hline Gram-positive & 11 & 0 & 1 & 91 \\
Gram-negative $_{\text {Control }^{2}}$ & 0 & 3 & 0 & 100 \\
Total correct & 0 & 0 & 3 & 100 \\
\hline
\end{tabular}

${ }^{1}$ The number of samples classified in the respective group by the ANN.

${ }^{2}$ Milk from cows without clinical mastitis and with low somatic cell count.

was able to differentiate between Staph. aureus, CNS, streptococci, and $E$. coli with a correct classification of $93 \%$. If only a classification between uninfected quarters, $E$. coli, and non- $E$. coli was needed, the correct classification rate was $94 \%$. These results show that mastitis pathogen classification using volatile bacterial metabolites looks very promising.

\section{REFERENCES}

Acree, T. E., and H. Arn. 2004. Subject: http://www.flavornet.org/. Accessed Feb. 27, 2007.

Arthur, C. L., and J. Pawliszyn. 1990. Solid-phase microextraction with thermal desorption using fused silica optical fibers. Anal. Chem. 62:2145-2148.

Barkema, H. W., Y. H. Schukken, T. J. G. M. Lam, M. L. Beiboer, H. Wilmink, G. Benedictus, and A. Brand. 1998. Incidence of clinical mastitis in dairy herds grouped in three categories by bulk milk somatic cell counts. J. Dairy Sci. 81:411-419.

Beltrán, N. H., M. A. Duarte-Mermoud, M. A. Bustos, S. A. Salah, E. A. Loyola, A. I. Peña-Neira, and J. W. Jalocha. 2006. Feature extraction and classification of Chilean wines. J. Food Eng. $75: 1-40$.

Bradley, A. J., K. A. Leach, J. E. Breen, L. E. Green, and M. J. Green. 2007. Survey of the incidence and aetiology of mastitis on dairy farms in England and Wales. Vet. Rec. 160:253-258.

Eriksson, A., K. Persson Waller, K. Svennersten Sjaunja, J. E. Haugen, F. Lundby, and O. Lind. 2005. Detection of mastitic milk using a gas-sensor array system (electronic nose). Int. Dairy J. 15:1193-1201.

Gardner, J. W., M. Craven, C. Dow, and E. L. Hines. 1998. The prediction of bacteria type and culture growth phase by an electronic nose with a multi-layer perceptron network. Meas. Sci. Technol. 9:120-127.

González-Arjona, D., G. López-Pérez, V. González-Gallero, and A G. González. 2006. Supervised pattern recognition procedures for discrimination of whiskeys from gas chromatography/mass spectrometry congener analysis. J. Agric. Food Chem. 54:19821989.

Heald, C. W., T. Kim, W. M. Sischo, J. B. Cooper, and D. R. Wolfgang. 2000. A Computerized mastitis decision aid using farm-based records: An artificial neural network approach. J. Dairy Sci. 83:711-720.

Marilley, L., S. Ampuero, T. Zesiger, and M. G. Casey. 2004. Screening of aroma-producing lactic acid bacteria with an electronic nose. Int. Dairy J. 14:849-856.

Marsili, R. T. 1999. SPME-MS-MVA as an electronic nose for the study of off-flavors in milk. J. Agric. Food Chem. 47:648-654.

Morales, P., I. Feliu, E. Fernandez-Garcia, and M. Nunez. 2004 Volatile compounds produced in cheese by Enterobacteriaceae strains of dairy origin. J. Food Prot. 67:567-573.

Neeser, N. L., W. D. Hueston, S. M. Godden, and R. F. Bey. 2006. Evaluation of the use of an on-farm system for bacteriologic culture of milk from cows with low-grade mastitis. J. Am. Vet. Med. Assoc. 228:254-260.

Nielen, M., Y. H. Schukken, and H. Hogeveen. 1994. Development of an on-line mastitis detection system within an integrated knowledge-based system for dairy management support. Vet. Res. 25:285-289.

NMC. 2004. Microbiological Procedures for Use in the Diagnostics of Bovine Udder Infection and Determination of Milk Quality. National Mastitis Council Inc., Madison, WI.

Ritter, W., and H. Hanni. 1960. The application of gas chromatography in dairying. II. Detection and determination of volatile fatty acids in dairy products and cultures. Milchwissenschaft 15:296-302.

Sears, P. M., B. S. Smith, P. B. English, P. S. Herer, and R. N. Gonzalez. 1990. Shedding pattern of Staphylococcus aureus from bovine intramammary infections. J. Dairy Sci. 73:2785-2789.

Specht, D. F. 1990. Probabilistic neural networks. Neural Netw. 3:109-118.

Turner, A. P. F., and N. Magan. 2004. Electronic noses and disease diagnostics. Nat. Rev. Microbiol. 2:161-166.

Yamagishi, N., Y. Jinkawa, K. Omoe, S. Makino, and K. Oboshi. 2007. Sensitive test for screening for Staphylococcus aureus in bovine mastitis by broth cultivation and PCR. Vet. Rec. 161:381-383.

Zar, J. H. 1999. Biostatistical Analysis. 4th ed. Prentice Hall, Upper Saddle River, NJ.

Zechman, J. M., S. Aldinger, and J. N. Labows Jr. 1986. Characterization of pathogenic bacteria by automated headspace concentration-gas chromatography. J. Chromatogr. A 377:4957.

Zorah, K. T., R. C. W. Daniel, and A. J. Frost. 1993. Detection of bacterial antigens in milk samples from clinical cases of bovine mastitis in which culture is negative. Vet. Rec. 132:208-210. 